\title{
Renal fractional flow reserve: Is it available to predict hypertension improvement after stenting?
}

We commend Kądziela et al. [1] for their excellent study entitled "Prognostic value of renal fractional flow reserve in blood pressure response after renal artery stenting (PREFER study)" evaluating a potential relationship between resting translesional pressures ratio $(\mathrm{Pd} / \mathrm{Pa}$ ratio), renal fractional flow reserve (rFFR) and blood pressure response after renal stenting. They concluded that physiological assessment of renal artery stenosis using $\mathrm{Pd} / \mathrm{Pa}$ ratio and rFFR did not predict hypertension response after stenting [1]. However, we have several concerns about the true value of rFFR.

First, in a study by Mitchell et al. [2], rFFR was measured in 17 subjects with refractory hypertension and renal artery stenosis at 3 months after stent. $86 \%$ of the patients with abnormal rFFR experienced improvement, compared to only $30 \%$ of those with normal rFFR $(\mathrm{p}=0.04)$. In another study carried by Leesar et al. [3], using rFFR to predict hypertension improvement after stenting, the area under receiver operating characteristic curve was 0.85 (95\% CI 0.76-0.94, sensitivity $73 \%$, specificity $88 \%$, predictive accuracy $79 \%$ ). Besides, the odds ratio of $\mathrm{rFFR}$ was 0.79 (95\% CI $0.69-0.90, \mathrm{p}=0.0007$ ) by univariate predictors at 12 months after stenting. Therefore, we could draw an opposite conclusion from the PREFER study that rFFR was a promising tool to identify patients likely to benefit from renal stent.

Second, the PREFER study designed the subgroups by $\mathrm{Pd} / \mathrm{Pa}$ ratio (cut-point $=0.9$ ) and $\mathrm{rFFR}$ (cut-point $=0.8$ ) [1]. However, Leesar et al. [3] have once employed the cut-point of rFFR $=0.90$ in predicting hypertension improvement after stenting, and Kądziela et al. [4] recommended the best accuracy point for $\mathrm{Pd} / \mathrm{Pa}$ ratio as 0.93 . Therefore, the threshold value should be further discussed considering the poor predictive value of rFFR.

Besides, Mangiacapra et al. [5] validated that translesional systolic pressure gradient (TSPG) $\geq 20 \mathrm{~mm} \mathrm{Hg}$ was highly predictive of hypertension improvement after renal stenting and useful for appropriate selection of stenting patients. In the
PREFER study, the diagnostic value of TSPG to predict hypertension response should be further analyzed in addition to a strong correlation with $\mathrm{Pd} / \mathrm{Pa}$ ratio $(\mathrm{r}=-0.89, \mathrm{p}<0.001)$ and $\mathrm{rFFR}$ $(\mathrm{r}=-0.86, \mathrm{p}<0.0001)$ [1], which could convince the uselessness of rFFR for predicting hypertension improvement.

Finally, only 35 hypertensive patients were enrolled and underwent renal stenting, although the recruitment was challenging [1]. The major concerns included the invasiveness and potential risk of extra procedure of pressure-wire across the stenosis. The limited size certainly reduced the reliability of rFFR in hypertension response. We noticed that all subjects underwent 64-detector computed tomography (CT) angiography examinations before the stent and after 6 months. Recently, noninvasive quantification of FFR by computational fluid dynamics applied to CT angiography has been validated by multicenter DISCOVER-FLOW study and DeFACTO trial [6]. Moreover, both studies suggested that the novel technology was also applicable to other common cardiovascular conditions and might be used to determine whether renal artery stenosis was significant [6]. Therefore, noninvasive rFFR will be a potential predictive tool and markedly promote the large size clinical trials of renal artery stent.

\section{Conflict of interest: none declared}

\section{References}

1. Kądziela J, Januszewicz A, Prejbisz A et al. Prognostic value of renal fractional flow reserve in blood pressure response after renal artery stenting (PREFER study). Cardiol J, 2013; 20: 418-422.

2. Mitchell JA, Subramanian R, White CJ et al. Predicting blood pressure improvement in hypertensive patients after renal artery stent placement: Renal fractional flow reserve. Catheter Cardiovasc Interv, 2007; 69: 685-689.

3. Leesar MA, Varma J, Shapira A et al. Prediction of hypertension improvement after stenting of renal artery stenosis: comparative accuracy of translesional pressure gradients, intravascular ultrasound, and angiography. J Am Coll Cardiol, 2009; 53: 2363-2371.

4. Kadziela J, Witkowski A, Januszewicz A et al. Assessment of renal artery stenosis Kadziela J, Witkowski A, Januszewicz A et al. Assessment of renal artery stenosis
using both resting pressures ratio and fractional flow reserve: relationship to using both resting pressures ratio and fractional flow reserve:
angiography and ultrasonography. Blood Press, 2011; 20: 211-217.

5. Mangiacapra F, Trana C, Sarno G et al. Translesional pressure gradients to predict blood pressure response after renal artery stenting in patients with renovascular hypertension. Circ Cardiovasc Interv, 2010; 3: 537-542.

6. Taylor CA, Fonte TA, Min JK. Computational fluid dynamics applied to cardiac computed tomography for noninvasive quantification of fractional flow reserve: scientific basis. J Am Coll Cardiol, 2013; 61: 2233-2241.

Yu Mao ${ }^{1 *}$, Xiaolong $Q i^{2 *}$, Wei Xu ${ }^{2 *}$, Lin Zhou ${ }^{1}$ (*Equal contributor)

${ }^{1}$ Division of Cardiology, Tongji Hospital, Tongji University School of Medicine, 389 XinCun Road, Shanghai 200065, China,

tel: +862166111046,fax: +862166111049,e-mail:linzhoutj@126.com

${ }^{2}$ Tongji Hospital, Tongji University School of Medicine, Shanghai 200065, China 